\title{
IV. On steam considered as a conductor of electricity
}

\section{Dr. Charles Schafhaeutl}

To cite this article: Dr. Charles Schafhaeutl (1841) IV. On steam considered as a conductor of electricity , Philosophical Magazine Series 3, 18:114, 14-17, DOI: $10.1080 / 14786444108650235$

To link to this article: http://dx.doi.org/10.1080/14786444108650235

曲 Published online: 01 Jun 2009.

Submit your article to this journal $\pi$

Џ Article views: 2

Q View related articles $\sqsubset$ 
which will be quite sufficient to show the correctness of my statement.

Required the result of dextans. siliqua. ceraces.

The reduction of dextans :

$$
\begin{aligned}
\text { dextans } & =\frac{\text { igin. sipos }}{\text { andras. calcis }}=\frac{\text { andras. quinas }}{\text { andras. calcis }}=\frac{\text { quinas }}{\text { calcis }} \\
& =\text { semiuncia. quicuux. }
\end{aligned}
$$

The very first step of which uses the decimal scale.

IV. On Steam considered as a Conductor of Electricity. By Dr. Charles Schafhaedti*.

T $N$ the last Number of the Philosophical Magazine, the 1 electricity obtained from a jet of high-pressure steam was considered to be of similar origin with that obtained from the insulated and separated positive metallic disc of Volta's Electrophorus.

On this point, the first question which presents itself is, in what relation does steam or water-gas stand with the conductors or non-conductors of electricity.

It is well known that moist air is a conductor of electricity, and dry air, viz. air which contains less water-gas than it is capable of containing according to its temperature, is a non-conductor of electricity; but, besides this, I am not aware of any experiment made to ascertain the conducting power of pure steam without being in contact with water or mercury, and $I$ therefore determined to ascertain this question by experiment.

The ends of a glass tube, about two inches long and a quarter inch interior diameter, were drawn out over a lamp to points, and bent upwards in a right angle. A thick platinum wire, with a small ring formed at each end, was then inserted into one end of the tube, and the glass melted around it air-tight. Water was then poured into the tube and boiled till only about two drops remained, when another platinum wire was inserted at the other end, and the hole quickly hermetically closed as before. The distance between the ends of the two wires in the tube was about one inch and a quarter, and the tube in this state contained of course nothing but water-gas and some liquid water.

This tube was now inserted close to the bulb of a thermometer into a small sand-bath $\dagger$, and covered with the sand, excepting the two vertical ends.

* Communicated by the Author, whose former communication on the subject appeared in our last Number; L. E. and D. Phil. Mag. vol. xvii. p. 449.

+ I cannot omit to mention the kindness I experienced from the gentlemen lecturing at the Adelaide Gallery, in allowing me the use of their 
One of these platinum wires was then connected with the outside of a Leyden jar, the other with an insulated discharger.

The Leyden jar, containing about 100 square inches armed surface, was now charged by means of fifty revolutions of a twelve-inch glass plate, and then discharged through the tube as usual. The glass tube acted exactly as an imperfect cronductor, interrupting the conducting wire, which connects the two surfaces of the jar, like a piece of wet cotton thread, or portion of glass tube moistened inside. The jar was perfectly discharged by the first touch, with that peculiar hissing noise and reddish fascicular stream of electricity which invariably occur under similar circumstances. The temperature of the sand-bath was now gradually raised, and at every 5 degrees a similar electric discharge from the Leyden jar was passed through the tube. The same results were obtained until the thermometer reached 250 degrees. At this point, by discharging the jar, a small red spark was obtained, instead of the former fascicular stream, and the jar was found to be entirely discharged, although the noise occasioned by the spark was scarcely audible, compared with the loud clap produced by the discharge of the jar under ordinary circumstances.

After the temperature had been elevated to 405 degrees, the contents of the jar discharged with the usual brilliant spark and loud report, and at the same time the spark was seen passing through the tube. At this time no moisture could be detected in the tube, and the water-gas contained in it had entirely ceased to be a conductor of electricity, at the same time giving less resistance to the passage of the spark than common air, the striking distance having been elongated from half an inch to one inch and a quarter. When the temperature was reduced below 405 degrees, the discharge passed as before mentioned, either as a small red spark, or in a fascicular stream, according to the temperature. When above 405 degrees the spark passed as usual, until the temperature rose to 443, when the tube burst, which prevented me from ascertaining its weight with and without the water; the difference of which would of course have given me the weight of the water contained in the tube, the cubical contents of which would have been ascertained by filling it with quicksilver. If we assume that there were two drops of water in the tube when it burst, weighing together 0.79 grains, and supposing the contents of the tube to be 500 cubic lines, we have the pressure of 23.5 atmospheres therein.

laboratory and philosophical apparatus for the purpose of making these experiments. Institutions of this description, which are to be found only in England, are invaluable to foreigners occupied in philosophical researches. 


\section{Dr. Schafhaeutl on Steam as an Electrical Conductor.}

From the preceding experiments we may conclude that steam, pure and free from contact with water, has, like all other gases, the property of being a non-conductor of electricity.

The facility with which the spark passes through the watergas seems to be worthy of attention; the striking distance of the spark having increased from half an inch to one inch and a quarter; for, according to Mr. Harris's discoveries, the striking distances are, in ordinary cases, in the inverse ratio to the density of the gas.

If we now consider the fact, that the electricity of a jet of condensed steam is, according to Mr. Armstrong's experiments, positive; that the quantity of electricity obtained from a jet of high-pressure steam is in proportion to its condensation; further, that the steam contained in the boiler presents no appearances of free electricity; and that, according to $\mathrm{Mr}$. Pattinson's experiments, both water and boiler are negative, which is a necessary consequence of Mr. Armstrong's experiments; - we perceive a simultaneous development of electric polarity in opposite directions from a central or neutral point, asin the magnetic steel-bar; and this development of electric polarity can only be ascribed to the opposite changes of molecular arrangements, as well as chemical condition of the water and steam column; and we must consider both electric poles as co-existent and not separately.

Volta's electrophorus is only remarkable for the property of retaining its electricity for a lengthened period, and its action is entirely due to induced electricity, with which no one will confound the electricity obtained from steam. Besides, the disc of the electrophorus, from which the spark is obtained, must be a perfect conductor well insulated, and shows signs of free electricity only when it is, after close contact with the electrophoric cake and neutralization of its free electricity, removed absolutely from the inducing cake. In a boiler filled with steam and water, neither of the above-mentioned circumstances can take place, and the positive electricity of the condensed steam, and the negative electricity of the boiler are the only points ascertained by experiment. The electricity developed by evaporation, as the source of the observed free electricity, is only hypothetical.

Volta's experiment, of splashing water on ignited charcoal, can scarcely be considered as identical with the evaporation of water in a boiler; in the first instance, a mass of chemical decomposition and changes are taking place which never can occur in the latter, for even the sudden cooling of substances is sufficient to produce signs of free electricity. 
If we ascribe the electricity of steam to its condensation, the circumstances under which that condensation takes place are likewise of great influence. The smallest jet of highpressure steam developes more free electricity than 100 times greater quantity of low-pressure steam;--another condition under which electricity is produced from a jet of steam, seems therefore to be its rapid expansion when issuing from the boiler; or probably, as $I$ have suggested on a former occasion, the quantity of caloric becoming latent during the expansion of high-pressure steam, has some relation to the quantity of electricity being set free. Even electricity in thunder-storms seems to be ascribable partially to the rapid currents of air whirling towards the centre of the clouds, as caloric is absorbed whilst the thunder-clouds are charging themselves.

V. Explanation of a Map, showing the Direction of the Wind at Noon, as observed at various Places, in the Storm of December 15, 1839. By W. C. REDFIELD, Esq.

THE arrows on the map, Plate I. denote, approximately, the direction of wind at noon at the several places of observation. The concentric lines, drawn at intervals of thirty miles, were added, not as precisely indicating the true course of the wind, but in order to afford better means of comparison for the several observations.

The assumed axis of the gale, at this time, should probably have been placed more to the westward, on a line with the position of the Morrison and Cape Cod Bay, at which points the gale was then blowing with great violence in opposite directions. The Morrison was from China, bound to New York, and I have reason to believe that her position may be safely relied on. The ship, as I am informed, was lying to at noon with bare poles, and had taken the western side of the gale suddenly at 7 A.M. This gale was severely felt in most of the region comprised in this map, excepting its northwestern and extreme northern portion, and excepting also the light winds which were found near the axis of the gale in the vicinity of Buzzard's Bay, \&c. in the afternoon and evening. A very heavy fall of snow accompanied the gale in the states of Connecticut, Rhode Island, Massachusetts, New Hampshire and Maine, also in parts of the states of New York and Vermont. Some snow also fell in the western and northern parts of New York and Vermont, but attended with moderate winds, chiefly from the north and north-west.

Abbreviations-N.H. New Hampshire-CMe. Maine-Ms. Massachu. setts.-R.I. Rhode Island, State.-Ct. Connecticnt.-L.I. Long Island.N.Y. New York, State. - N. J. New Jersey. Note. My observations on the 15th P.M. have on a former occasion been erroneously printed N.W. by W.; read N.W. by N.

Phil. Mag. S. 3. Yol, 18. No, 114. Jan. 1841. C 